\title{
STRUKTUR LOKAL PADA SEMIGRUP LEGAL
}

\section{LOCAL STRUCTURE ON LEGAL SEMIGROUPS}

\author{
Soffi Widyanesti Priwantoro ${ }^{\text {a) }}$ Sri Wahyuni ${ }^{\text {b) }}$ \\ ${ }^{a)}$ Program Studi Pendidikan Matematika FKIP UAD \\ soffi_dyan@gmail.com \\ b) Jurusan Matematika FMIPA UGM \\ swahyuni@ugm.ac.id
}

\begin{abstract}
ABSTRAK
Pada artikel ini akan dibahas mengenai latar belakang munculnya semigrup nonreguler yang berhubungan dengna sifat dasar dari semigrup regular. Salah satu semigrup nonreguler yang akan dibahas di artikel ini adalah semgirup legal.

Dari salah satu proposisi mengenai pasangan suatu elemen di semigrup reguler yaitu, $S$ suatu semigrup regular dan a, b $\in \mathrm{S}$, berlaku: 1) $(a, b) \in \mathcal{L}$ jika dan hanya jika $\left.\left(\exists \mathrm{a}^{\prime} \in \mathrm{V}(\mathrm{a}), \mathrm{b}^{\prime} \in \mathrm{V}(\mathrm{b})\right) \quad \exists \mathrm{a}^{\prime} \mathrm{a}=\mathrm{b}^{\prime} \mathrm{b} ; 2\right)(a, b) \in \mathcal{R}$ jika dan hanya jika $\left(\exists a^{\prime} \in V(a), b^{\prime} \in\right.$ $\left.V(a)) \ni a a^{\prime}=b b^{\prime} ; 3\right)(a, b) \in \mathcal{H}$ jika dan hanya jika $\exists a^{\prime} \in V(a), b^{\prime} \in V(b) \ni a^{\prime} a=$ $b^{\prime} b \& a a^{\prime}=b b^{\prime}$. Kemudian akan diperkenalkan pasangan suatu elemen untuk suatu semigrup sebarang yaitu, $S$ suatu semigrup sebarang dan $a, b \in S$ didefinisikan:1)pasangan $(a, b)$ disebut pasangan kanan jika $a b a=b a ; 2)$ pasangan $(a, b)$ disebut pasangan kiri jika $a b a=a b$. Selanjutnya akan diselidiki hubungan pasangan untuk semigrup sebarang tersebut dengan semigrup reguler.

Selanjutnya akan ditunjukkan bagaimanakah struktur lokal dari semigrup legal yang dibentuk dari disjoint union dari band like semigrup sederhana, yaitu $S=\mathrm{\cup}_{\alpha \in Y} S_{\alpha}$.

Kata kunci: semigrup regular lengkap, semigrup legal, band nol kiri, band nol kanan
\end{abstract}

\begin{abstract}
In this article will talk about how non-regular semigroup appear which is have relation with a basic theorem of regular semigroup. One of the non-regular semigroup which is talk in this article is legal semigroups.

One of the theorem about pairs of elements in regular semigroups is, $S$ is regular semigroups and $\mathrm{a}, \mathrm{b} \in \mathrm{S}$, apply: 1$)(a, b) \in \mathcal{L}$ if and only if $\left(\exists \mathrm{a}^{\prime} \in \mathrm{V}(\mathrm{a}), \mathrm{b}^{\prime} \in \mathrm{V}(\mathrm{b})\right) \quad \ni$ a' $\mathrm{a}=$ $\left.\mathrm{b}^{\prime} \mathrm{b} ; 2\right)(a, b) \in \mathcal{R}$ if and only if $\left.\left.\left(\exists a^{\prime} \in V(a), b^{\prime} \in V(a)\right) \ni a a^{\prime}=b b^{\prime} ; 3\right)\right)(a, b) \in \mathcal{H}$ if and only if $\exists a^{\prime} \in V(a), b^{\prime} \in V(b) \exists a^{\prime} a=b^{\prime} b \& a a^{\prime}=b b^{\prime}$. Then will be introduced about pairs of elements for arbitrary semigroups i.e, $S$ is an arbitrary semigroups and $a, b \in S$ defined: 1$)(a, b)$ called right pairs if $a b a=b a ; 2)(a, b)$ called left pairs if $a b a=a b$. Then will be explored about the relation of pairs for arbitrary semigroups with regular semigroups..

Then will be shown how local structure of legal semigroups formed from union disjoint of band-like simple semigroups, i.e: $S=\mathrm{U}_{\alpha \in Y} S_{\alpha}$.

Keyword : Complete Regular Semigroup, Legal semigroup, Left-zero band, Right-zero band
\end{abstract}




\section{Pendahuluan}

Pada semigrup reguler dapat didefinisikan suatu relasi ekuivalensi yang dinamakan relasi ekuivalensi Green. Terdapat lima relasi pada relasi ekuivalensi Green tersebut yaitu relasi yang dinotasikan dengan $\mathcal{L}, \mathcal{R}, \mathcal{H}, \mathcal{J}$, dan $\mathcal{D}$. Selanjutnya terdapat proposisi pada relasi ekuivalensi Green yang membahas mengenai pasangan-pasangan pada suatu semigrup reguler, yaitu:

Teorema 1.1 (Howie, 1976) Jika $a, b \in S$, dan $S$ adalah semigrup reguler, maka

1. $(a, b) \in \mathcal{L}$ jika dan hanya jika $\left(\exists a^{\prime} \in V(a), b^{\prime} \in V(b)\right) \quad a^{\prime} a=b^{\prime} b$

2. $(a, b) \in \mathcal{R} j i k a$ dan hanya jika $\left(\exists a^{\prime} \in V(a), b^{\prime} \in V(a)\right) a a^{\prime}=b b^{\prime}$

3. $(a, b) \in \mathcal{H}$ jika dan hanya jika $\left(\exists a^{\prime} \in\right.$ $V(a), b^{\prime} \in V(b) a^{\prime} a=b^{\prime} b \quad \& a a^{\prime}=$ $b b^{\prime}$

Berikut akan diperkenalkan konsep pasangan kanan dan pasangan kiri dari suatu semigrup sebarang.

Definisi 1.2 (Kar Ping Shum, 2000) Diberikan semigrup $S$ sebarang untuk $a, b \in S$ Didefinisikan:

i) Pasangan $(a, b)$ disebut pasangan kanan jika $a b a=b a$

ii) Pasangan $(a, b) \quad$ disebut pasangan kiri jika $a b a=a b$

Pada teorema selanjutnya akan diselidiki hubungan antara pasangan kanan dan pasangan kiri di semigrup reguler.

Teorema 1.3 (Kar Ping Shum, 2000) Jika $S$ semigrup regular dan $a, b \in S$, maka kondisi dibawah ini ekuivalen

1. Untuk setiap $a, b \in S$ berlaku salah satu yaitu:

i) $(a, b)$ dan $(b, a) \quad$ keduanya pasangan kanan, atau ii) $(a, b)$ dan $(b, a) \quad$ keduanya pasangan kiri

2. Untuk setiap $a, b \in S$ berlaku salah satu yaitu:

i) $(a, b)$ pasangan kanan; atau

ii) $(a, b)$ pasangan kiri.

3. $S$ adalah band dan setiap kelas $\mathcal{D}$ dari $S$ adalah band nol kanan atau band nol kiri.

Bukti:

$(1 \Rightarrow 2)$ Diketahui $\quad(a, b)$ dan $(b, a)$ adalah pasangan kanan jadi $(a, b)$ merupakan pasangan kanan juga. Hal ini juga berlaku untuk $(a, b)$ dan $(b, a)$ adalah pasangan kiri.

$(2 \Rightarrow 3) \quad$ Diketahui $\quad(a, b) \quad$ adalah pasangan kanan atau $(a, b)$ pasangan kiri. Kemudian akan ditunjukkan bahwa $\mathrm{S}$ adalah band. Diketahui $(a, b)$ pasangan kanan, sehingga berlaku $a b a=b a$. Diambil $a \in S$ dan $a^{\prime} \in V(a)$ yang berarti berlaku $a a^{\prime} a=a$ dan $a^{\prime} a a^{\prime}=a^{\prime}$ dan $a a^{\prime}, a^{\prime} a \in E(S)$. Selain itu telah diketahui bahwa $a a^{\prime} a=a$ dan $a a^{\prime} a=$ 
$a^{\prime} a$, sehingga $a=a a^{\prime} a=a^{\prime} a$. Karena $a^{\prime} a \in E(S)$ dan $a=a^{\prime} a$ maka $a \in E(S)$, sehingga $S$ adalah suatu band. Kemudian diketahui juga $(a, b)$ pasangan kiri, yang berarti bahwa $a b a=a b . \quad$ Karena $a a^{\prime} a=a \quad$ dan $\quad a a^{\prime} a=a a^{\prime} . \quad$ Telah diketahui bahwa $a a^{\prime} \in E(S)$, diperoleh $a=a a^{\prime} a=a a^{\prime}$, dengan kata lain $a \in E(S)$. Hal ini dapat disimpulkan bahwa baik $(a, b)$ pasangan kiri atau pun pasangan kanan $S$ merupakan band. Kemudian akan ditunjukkan bahwa setiap kelas $\mathcal{D}$ dari $S$ adalah band nol kanan atau band nol kiri. Karena $\mathrm{S}$ adalah suatu band menurut A.H Clifford (1954) maka $S$ adalah semilatis dari band rectangular. $S$ dapat ditulis $S=\cup_{\alpha \in Y} \mathbb{D}_{\alpha}$ dimana tiap $\mathbb{D}_{\alpha}$ adalah band rectangular dan $Y$ adalah semilatis. Selanjutnya, klaim bahwa tiap $\mathbb{D}_{\alpha}$ adalah band nol kanan atau band nol kiri. Ambil $a \in \mathbb{D}_{\alpha}$, jika $(a, b)$ adalah pasangan kanan untuk suatu $b \in$ $\mathbb{D}$ dengan $b \neq a$ maka untuk semua $x \in \mathbb{D}(a, x)$ adalah pasangan kanan, seblaiknya dapat ditemukan juga $c \in \mathbb{D}$ dengan $c \neq a$ dimana $(a, c)$ bukan pasangan kanan. Hal ini berarti $(a, c)$ adalah pasangan kiri berlaku $a c a=a c$ dan $a, c \in \mathbb{D}_{\alpha}$ maka berlaku aca $=$ a dan cac $=c \quad$ dan juga berlaku $c a=c a c$ jadi diperoleh $a c=a$ dan $c a=c$. Demikian pula berlaku untuk $(a, b)$ pasangan kanan dan $\mathbb{D}_{\alpha}$ suatu band rectangular, diperoleh $\quad a b a=$ $b a$ dan $a b a=a \quad$ serta $\quad b a b=$ $a b$ dan $b a b=b$ atau dengan kata lain diperoleh $\quad b a=a$ dan $a b=b$. Disamping itu ada beberapa kasus yaitu: i) jika $(b, c)$ adalah pasangan kanan maka $b c b=c b \quad$ karena $\quad b, c \in \mathbb{D}_{\alpha}$ diperoleh $b=c b$ dan $c=b c$. Kemudian diperoleh $c=c a=c b a=b a=a$. terjadi kontradiksi karena $c \neq a$.

ii) jika $(b, c)$ adalah pasangan kiri maka $b c b=b c \quad$ karena $\quad b, c \in \mathbb{D}_{\alpha} \quad$ diperoleh $b=b c$ dan $c=c b$. Kemudian diperoleh $b=b c=a b c=a c=a, \quad$ terjadi kontradiksi karena $b \neq a$.

Diperoleh bahwa $\quad x \in \mathbb{D}_{\alpha}, \quad(a, x)$ pasangan kanan, sehingga $\mathbb{D}_{\alpha}$ adalah suatu band nol kanan.

$(3 \Rightarrow 1)$ Diketahui: $\mathrm{S}$ adalah band dan Setiap kelas $\mathcal{D}$ dari $\mathrm{S}$ adalah band nol kanan atau band nol kiri. Kemudian kita misalkan $S=\cup_{\alpha \in Y} \mathbb{D}_{\alpha} \quad$ dekomposisi semilatis $\mathbb{D}_{\alpha}$ pada semilatis $Y$, dengan $\mathbb{D}_{\alpha}$ adalah band nol kanan atau kiri. $\forall e, f \in S$ kita dapatkan $e \in \mathbb{D}_{\alpha} \operatorname{dan} f \in$ $\mathbb{D}_{\beta}$ untuk $\alpha, \beta \in Y$. Dengan struktur semilatsi $\cup_{\alpha \in Y} \mathbb{D}_{\alpha}$ maka diperoleh ef, fe $\in \mathbb{D}_{\gamma}$ dengan $\gamma=\alpha \beta$. Jika $\mathbb{D}_{\gamma}$ band nol kanan maka diperoleh, efe $=$ effe $=(e f)(f e)=f e$ dan $f e f=f e e f=(f e)(e f)=e f$ 
dengan kata lain $(e, f) \operatorname{dan}(f, e)$ adalah pasangan kanan. Jika $\mathbb{D}_{\gamma}$ band nol kiri diperoleh

efe $=(e f)(f e)=$ ef dan $f e f=$ $(f e)(e f)=f e$

dengan kata lain $(e, f) \operatorname{dan}(f, e)$ merupakan pasangan kiri.

Teorema 1.4 (Kar Ping Shum, 2000) Jika diketahui $S$ semigrup yang memenuhi $S^{2} \subseteq E(S)$ maka kondisi (1) dan (2) pada teorema 3.1.4 ekuivalen.

Bukti.

$(1 \Rightarrow 2)$ Diketahui $(a, b)$ dan $(b, a)$

pasangan kanan. Kemudian akan ditunjukkan $(a, b)$ pasangan kanan. Karena $(a, b)$ dan $(b, a)$ kedua-duanya pasangan kanan maka $(a, b)$ pasangan kanan juga.

$(2 \Longrightarrow 1)$ Diketahui $(a, b)$ pasangan kanan dan $S^{2} \subseteq E(S)$. Kemudian akan ditunjukkan $(a, b)$ dan $(b, a)$ keduaduanya pasangan kanan. Dari yang diketahui terlihat bahwa $(a, b)$ pasangan kanan yang berarti $a b a=b a \quad \forall a, b \in S$. Sekarang akan ditunjukan bahwa $(b, a)$ pasangan kanan juga. Diketahui $(a, b)$ pasangan kanan yang berarti $a b a=$ ba $\forall a, b \in S$ karena $S^{2} \subseteq E(S)$ maka $b \in S^{2} \subseteq E(S)$. Diperoleh bahwa $a b \in E(S)$ yang berarti:

$$
\begin{aligned}
& (a b)^{2}=a b \\
& b a b=(b a) b=(a b a) b=(a b)^{2}=a b,
\end{aligned}
$$

sehingga diperoleh $b a b=a b$ dengan kata lain $(b, a)$ adalah pasangan kanan.

Untuk $\quad(a, b)$ dan $(b, a) \quad$ keduanya pasangan kiri $\Leftrightarrow(a, b)$ pasangan kiri akan ditunjukkan sebagai berikut, yaitu $(1 \Rightarrow 2)$ Diketahui $\quad(a, b)$ dan $(b, a)$ pasangan kiri. Kemudian akan ditunjukkan $(a, b)$ pasangan kiri. Karena $(a, b)$ dan $(b, a)$ kedua-duanya pasangan kiri maka $(a, b)$ pasangan kiri juga. $(2 \Rightarrow 1)$ Diketahui $(a, b)$ pasangan kiri dan $\quad S^{2} \subseteq E(S) . \quad$ Kemudian akan ditunjukkan $(a, b)$ dan $(b, a)$ keduaduanya pasangan kiri. Dari yang diketahui terlihat bahwa $(a, b)$ pasangan kiri yang berarti $a b a=a b \quad \forall a, b \in S$. Sekarang akan ditunjukan bahwa $(b, a)$ pasangan kiri juga, yaitu $b a b=b a$. Diketahui $(a, b)$ pasangan kiri yang berarti $a b a=a b \quad \forall a, b \in S \quad$ karena $S^{2} \subseteq E(S) \quad$ maka $\quad a \in S^{2} \subseteq E(S)$. Diperoleh bahwa $b a \in E(S)$ yang berarti $(b a)^{2}=b a$.

$b a b=b(a b)=b(a b a)=(b a)^{2}=b a$, sehingga diperoleh $b a b=b a$ dengan kata lain $(b, a)$ adalah pasangan kiri. Jadi diperoleh kesimpulan bahwa untuk $S$ suatu semigrup yang memenuhi $S^{2} \subseteq$ $E(S)$ maka kondisi (1) dan (2) pada teorema 3.1.4 ekuivalen.

Dari teorema diatas terlihat bahwa semigrup non-reguler $S$ memenuhi kondisi (1) pada teorema 3.1.4. Dari sini 
maka didefinisikan mengenai semigrup legal, sebagai berikut:

Definisi 1.5 (Kar Ping Shum, 2000) Semigrup S sebarang disebut semigrup legal jika kondisi (1) pada teorema 3.1.4 dipenuhi, yaitu untuk semиa $a, b \in S$ berlaku salah satu yaitu:

i) $(a, b)$ dan $(b, a) \quad$ keduanya adalah pasangan kanan jika berlaku: $a b a=b a$ dan $b a b=a b, a t a u$ ii) $(a, b)$ dan $(b, a) \quad$ keduanya adalah pasangan kiri jika berlaku: $a b a=a b$ dan $b a b=b a$.

\section{Hasil dan Pembahasan}

Pada penulisan paper ini membahas tentang struktur lokal semigrup legal. Pada semigrup reguler $S$, jika untuk setiap $a \in S$ terdapat $x \in S$ sedemikian sehingga $a x=x a$ maka $S$ merupakan semigrup reguler lengkap. Berdasarkan teorema yang dibahas oleh Mario Petrich (1999) semigrup reguler lengkap dapat dikatakan juga sebagai gabungan dari grup. Selanjutnya Kar Ping Shum dan Ping Yu Zhu (2000) memperkenalkan struktur lokal dari semigrup legal.

Teorema 2.1 (Kar Ping Shum, 2000) Jika $S$ adalah semigrup legal, maka untuk semua $a \in S$ terdapat $e \in S$ sedemikian sehingga ae $=e a=e$.

Bukti:

Diambil $a \in S$, karena $S$ adalah semigrup legal berarti $a a a=a a$ dengan kata lain $a^{3}=a^{2}$. Diambil $a^{2}=e$ maka $a^{3}=a a^{2}=a e=e . \quad$ Selain itu juga diperoleh $a^{3}=a^{2} a=e a=e$. Dengan demikian diperoleh $a e=e a=e$.

Proposisi 2.2 (Kar Ping Shum, 2000) Untuk $a, b \in S$. Jika $a^{2}=b^{2}=e$ maka $a b=e$.

Bukti:

$S$ suatu semigrup legal, diambil $a, b \in S$, pasangan kanan $(a, b)$ dan $(b, a)$ pada $S$ $b a b=a b$ berarti $a b a=b a$,diperoleh $e a b=b^{2} a b=b(b a b)=b(a b)=a b$.

Sedangkan menurut teorema 2.1, didapatkan $e a b=(e a) b=e b=e$, sehingga diperoleh $e=a b$. Kemudian untuk $(a, b)$ dan $(b, a)$ pada $S$ suatu pasangan kiri, yang berlaku $b a b=$ $b a$ berarti $a b a=a b . \quad$ Untuk menunjukkan bahwa $a b=e$ dengan $(a, b)$ dan $(b, a)$ pasangan kiri, yaitu $a b e=a b\left(a^{2}\right)=(a b a) a=(a b) a=a b$, sedangkan menurut teorema 2.1 didapatkan $\quad a b e=a(b e)=a e=e$, sehingga diperoleh $a b=e . \quad$ Dengan begitu dapat diambil kesimpulan bahwa untuk $S$ suatu semigrup legal dengan $(a, b)$ dan $(b, a)$ pasangan kanan atau pun pasangan kiri diperoleh $a b=e$.

Akibat 2.3 (Kar Ping Shum, 2000) Jika $e \in E(S) \quad$ dan $\quad S_{e}=\left\{a \in S \mid a^{2}=e\right\}$, maka $S_{e}$ adalah subsemigrup dari $S$.

Bukti. 
Diketahui $S_{e}=\left\{a \in S \mid a^{2}=e\right\} e \in E(S)$, diambil $a, b \in S_{e}$ dengan $a, b \in S$ dimana $a^{2}=e$ dan $b^{2}=e$. Akan ditunjukkan $a . b \in S_{e}$ yaitu $(a b)^{2}=e$ dengan $a b \in$ $S, \quad$ yaitu $(a b)(a b)(a b)=b a b a b=$ $a b a b=b a b=a b$. Jadi $a b \in S$ dengan $(a b)^{2}=(a b)(a b)=a b b=a b^{2}=$ $a e=e$. Karena $a b \in S$ dengan $(a b)^{2}=$ $e$, maka terbukti bahwa $S_{e}$ adalah subsemigrup dari $S$.

Teorema 2.4 (Kar Ping Shum, 2000) Diketahui $e, f \in \mathbb{D}_{\alpha}$ untuk suatu $\alpha \in Y$ dan $\mathbb{D}_{\alpha}$ adalah band nol kiri atau band nol kanan. Jika $a, b \in S$ sedemikian sehingga $a^{2}=e \in E(S)$ dan $b^{2}=f \in$ $E(S)$ maka $a b \in \mathbb{D}_{\alpha}$.

Bukti:

Diambil $\mathbb{D}_{\alpha}$ adalah suatu band nol kanan maka, karena $e \mathcal{R} f$, diperoleh $e f=f$ dan $f e=e .(a, b)$ dan $(b, a)$ pasangan kanan berarti $a b a=b a$ dan $b a b=a b$. Dengan menggunakan proposisi 3.2.1 yaitu $\forall a \in S \exists e \in S \quad \exists a e=e a=e$ diperoleh $\quad(a b) f=a(b f)=a f=$ $a(e f)=(a e) f=e f=f$. Dan, $f(a b)=$ $b^{2} a b=b(b a b)=b a b=a b$,

karena $(a b) f=f$ dan $f(a b)=a b$ maka $f \mathcal{R} a b$ dengan kata lain $a b \in \mathbb{D}_{\alpha}$. Dengan cara yang sama untuk $(a, b)$ dan $(b, a)$ pasangan kiri diperoleh:

$(a b) e=(a b) f e=a(b f) e=a(f e)=$ $a e=e$
Dan, $(a b) e=(a b) a^{2}=(a b a) a=$ $a b a=a b$.

Jadi $(a b) e=e$ dan $(a b) e=a b$ dengan kata lain a $b=e$, sementara $e \in \mathbb{D}_{\alpha}$ sehingga $a b \in \mathbb{D}_{\alpha}$.

Definisi 2.5 (Kar Ping Shum, 2000) Semigrup $S$ dikatakan band-like semigrup sederhana, jika untuk setiap $a \in S, a^{2} \in E(S)$ dengan $E(S)$ adalah band nol kanan atau band nol kiri di $S$.

Dengan menggunakan teorema 2.4, akan diberikan struktur lokal pada semigrup legal $\mathrm{S}$.

Teorema 2.6 (Kar Ping Shum, 2000) S semigrup dengan $E(S)=\cup_{\alpha \in Y} \mathbb{D}_{\alpha}$, dengan $\mathbb{D}_{\alpha}$ adalah band nol kanan atau band nol kiri dan $S_{\alpha}$ elemen himpunan band-like dari $S$, yaitu, $S_{\alpha}=$ $\left\{a \in S \mid a^{2} \in E(S)\right\} \quad$ tiap $\quad \alpha \in Y . \quad$ Maka pernyataan berikut berlaku pada semigrup legal $S$.

1) $S_{\alpha}$ adalah subsemigrup dari $S$

2)S disjoint union dari band-like semigrup sedehana $S_{\alpha}$, yaitu,

$$
S=\cup_{\alpha \in Y} S_{\alpha}
$$

Bukti:

1) Diketahui $S_{\alpha}=\left\{a \in S \mid a^{2} \in E(S)\right\}$ dengan $S_{\alpha}$ elemen himpunan band-like dari $S$ suatu semigrup dengan $E(S)=\cup_{\alpha \in Y} \mathbb{D}_{\alpha}$, sehingga diambil $a, b \in \mathrm{S}_{\alpha}$ yang berarti $a \in \mathrm{S}_{\alpha}=\left\{a \in S \mid a^{2} \in E(S)\right\} \quad$ dan $b \in \mathrm{S}_{\alpha}=\left\{b \in S \mid b^{2} \in E(S)\right\}$. Akan 
ditunjukkan

$a b \in \mathrm{S}_{\alpha}=\{a b \in$

$\left.S \mid(a b)^{2} \in E(S)\right\}$.

Diketahui

$a^{2} \in E(S)$ dan $b^{2} \in E(S)$, dengan $E(S)=\cup_{\alpha \in Y} \mathbb{D}_{\alpha}$ berarti $a^{2} \in \mathbb{D}_{\alpha}$ dan $b^{2} \in \mathbb{D}_{\beta}$ berdasarkan struktur semilatis diperoleh bahwa $a^{2} b^{2}, b^{2} a^{2} \in \mathbb{D}_{\gamma} \quad$ dengan $\gamma=\alpha \beta$, sehingga $(a b)(a b)=a b a b=$ $b a b=a b=a^{2} b^{2}$. Jadi diperoleh $(a b)^{2} \in \mathbb{D}_{\gamma} \quad$ jadi $\quad(a b)^{2} \in E(S)$. Jadi $S_{\alpha}$ adalah subsemigrup dari $S$.

2) Dari (1) diperoleh bahwa $S_{\alpha}$ adalah subsemigrup dari $S$ menurut Howie (1976) dapat diperoleh bahwa $S$ adalah disjoint union dari subsemigrup $S_{\alpha}(\alpha \in Y)$.

\section{Kesimpulan}

Kesimpulan yang dapat diambil dari penulisan paper ini adalah dari definisi tentang pasangan kanan dan pasangan kiri pada suatu semigrup sembarang yaitu untuk $S$ suatu semigrup sebarang dan $a, b \in S$ berlaku:1)Pasangan $(a, b)$ disebut pasangan kanan jika $a b a=b a$ dan ii)Pasangan $(a, b)$ disebut pasangan kiri jika $a b a=a b$. Jika $S$ semigrup yang memenuhi $S^{2} \subseteq E(S)$ maka i) $(a, b)$ dan $(b, a)$ keduanya pasangan kanan atau ii) $(a, b)$ dan $(b, a)$ keduanya adalah pasangan kiri berlaku $a b a=a b$ dan $b a b=$ $b a$. Dan struktur lokal dari semigrup legal adalah $S=\cup_{\alpha \in Y} S_{\alpha} \quad$ dengan $\quad S_{\alpha}=$ $\left\{a \in S \mid a^{2} \in E(S)\right\} \quad \forall \alpha \in Y$ dan $E(S)=$ $\cup_{\alpha \in Y} \mathbb{D}_{\alpha}, \mathbb{D}_{\alpha}$ adalah band nol kanan atau band nol kiri.

\section{Pustaka}

Howie, J.M.: An Introuction To Semigroup Theory, Oxford University Press, 1976

Kar Ping Shum.: On Legal Semigroups, Southeast Asian Bulletin Of Mathematics 24, 455-462, 2000

Clifford, A.H and Prreston, G.B: The Algebraic Theory Of Semigroups, Vol. I, Math. Surveys Of The American Math.Soc. 7, Providence, R.I., 1961

Clifford, A.H.:Bands Of Semigroups, Proc. Amer.Math.Soc. 5, 499-504 (1954) 